\title{
UN Food System Summit Fails to Address Real Healthy and Sustainable Diets Challenges
}

\author{
Janine Giuberti Coutinho ${ }^{1} \cdot$ Ana Paula Bortoletto Martins ${ }^{1} \cdot$ Potira V. Preiss $^{2} \cdot$ Lorenza Longhi $^{3} \cdot$ Elisabetta Recine $^{4}$
}

Published online: 20 October 2021

(c) Society for International Development 2021

\begin{abstract}
Evidence of the impacts of corporate food systems on people's health raised concerns about the multiple outcomes of malnutrition and climate change, including commodities production and high consumption of ultra-processed food products. The COVID-19 pandemic overwhelms this scenario, highlighting the urgency for improvements in governance spaces and regulatory measures that can tackle the advance of large corporations, which act exclusively based on their private interests.
\end{abstract}

Keywords Consumption · Healthy eating $\cdot$ Ultra-processed foods $\cdot$ Food and nutrition governance $\cdot$ Corporate capture

The COVID-19 pandemic is undoubtedly the major challenge facing countries in recent decades. Even with remarkable advances in vaccine development, we remain shrouded in more uncertainty rather than confidence. Millions of lives have been directly lost to the coronavirus, in addition to several other factors that continue to impact the lives of most people. If, at any time, it was thought that the pandemic would affect everyone equally, different contexts and situations around the planet have highlighted the weight of enormous inequalities and inequities in which we are all immersed (CSM 2020; Mendes et al. 2021).

The pandemic exacerbated long-standing structural problems, increasing the exposure of hundreds of millions of people worldwide to vulnerable situations. This is particularly true with regards to current food and nutrition security. The increase in poverty, in unemployment rates, loss of income (World Bank 2020; ILO 2021; Berkhout et al.

Janine Giuberti Coutinho

janine.giuberti@idec.org.br

Potira V. Preiss

potira@unisc.br

1 Brazilian Institute of Consumer Defense (IDEC), São Paulo, SP, Brazil

2 Graduate Program in Regional Development, University of Santa Cruz do Sul (UNISC), Santa Cruz do Sul, RS, Brazil

3 Independent Consultant, Brasília, DF, Brazil

4 University of Brasilia (UNB), Brasília, DF, Brazil
2021) and ability to purchase food are some of the dimensions among many others that have been and will be aggravated. Other dimensions continue to unfold, such as families migrating to cheaper and less healthy food, opening up more space for the sale of ultra-processed products from large corporations and retail chains. During the pandemic, multinationals such as Coca-Cola, McDonald's, and Nestlé engaged in marketing strategies appealing to comfort people (GHAI 2020; Franck and Prapha 2021). The latest data confirms that during the COVID-19 pandemic there was a general reduction in access to healthy foods such as fruits and vegetables, alongside increased consumption of ultra-processed products, formulations of substances obtained through the fractionation of fresh food (Nupens 2021) that are already proven to be highly harmful to health and the environment (The Lancet Diabetes and Endocrinology 2021).

Increasingly concentrated corporate global supply chains have a clear impact on the types of food that is offered and, therefore, on food consumption (IPES 2017). This is not a spontaneous situation, but the result of an architecture built to meet the interests and increasing demands of corporations rather than health and nutrition. Corporate interests have been shaping up since the change in land use with the growing production of commodities instead of real food, leading to loss of biodiversity, restricting food richness and diversity, and dumping the material needed to produce more and more ultra-processed food products. The increased use of land for intensive agricultural production has used natural resources (soil, water, plant and animal biodiversity) in an abusive and predatory way, generating contamination and 
scarcity of these resources, causing a continuous emission of greenhouse gases (De Laurentiis et al. 2016).

As if it were not bad enough, food corporations took advantage of the COVID-19 pandemic to expand their marketing strategies by using 'solidarity' actions. In fact, these strategies can be considered as 'health washing' and 'social washing'. Large industries-always on the lookout for new market opportunities-have reinforced their marketing actions with solidarity-based initiatives, donating and promoting their ultra-processed food products, appearing socially responsible but actually engaging in practices that contribute to aggravate health conditions and inequalities. The report 'Facing Two Pandemics How Big Food Undermined Public Health in the Era of COVID-19' exposes how the lack of healthy food regulations worldwide enabled food corporations to use the global COVID-19 crisis. An example in the US is Coca-Cola partnership with Uber Eats to donate one meal to Feeding America for every order placed (GHAI 2020).

How damaging these initiatives are for the food security, nutrition, health and livelihoods of consumers, small farmers, fishermen and many other food systems workers-as well as for climate emergencies-will depend largely on government policy responses in the short, medium and long term, including the strengthening of governance spaces and the crucial regulatory role of states. These and many other fundamental topics were not included in the UN Food Systems Summit's agenda.

\section{Overlapping of Pandemics}

FAO data indicate that in 2020 around 811 million people were in a state of hunger, making this situation more severe in the countries of the southern hemisphere, affecting $21 \%$ of the population in Africa, 9.1\% in Latin America and the Caribbean and 9\% in Asia (FAO et al. 2021). When considering the prevalence of food insecurity, 2.37 billion people did not have access to adequate food in 2020 and 38.9 million people are overweight, thus showing the double burden of malnutrition (FAO et al. 2021).

With regards to climate, the latest science report of The Intergovernmental Panel on Climate Change-IPCC (2021) indicates that we have reached a point of no return in terms of environment impact. There is clear evidence that human activities have warmed up the inhabited regions across the globe, with irreversible change within our lifetimes. Even considering the emissions cutback due to the COVID-19 pandemic, the concentrations of carbon dioxide in the atmosphere reached 419 parts per million, a level the planet has not seen for at least 2 million years (IPCC 2021).

The synergistic way that those pandemics interact and reinforce each other has led to the Global Syndemic perspective: a way to highlight the common underlying societal drives and intricate impact on both human and planetary health (Swinburn et al. 2019). In the core of the Syndemic are food systems that have generated strong impacts, being unable to provide quality food for society, and leading diets to become a risk factor in noncommunicable diseases (NCDs) that are responsible for $71 \%$ of all deaths globally, an equivalent of 41 million people each year (GBD 2015).

Food systems are also one of the main drivers of climate change. The intense livestock production, use of pesticides, and changes in use of the soil, plus the impact of industrialized food production and long-distance transport chains, are major sources of greenhouse gas (GHG) emissions. We must also consider that much agricultural production is not directed to human consumption, but to feed animals in the intensive production of meat ( $97 \%$ of soybeans and $40 \%$ of cereals produced in the world) or to produce biofuels (7\%), both using intense natural and financial resources (Alsaffar 2016).

With such robust evidence on the impacts of corporate food systems on the health of people and the planet, aggravated by the event of the Covid-19 pandemic, the Summit had in its hands the opportunity to promote a historic debate, supported by transparent, representative governance structures, such as the reformed Committee of United Nations Food Security (Canfield et al. 2021).

\section{What the Food System Summit is not Addressing towards a Healthy and Sustainable Food and Nutrition System Agenda}

The United Nations Food Systems Summit (FSS) was expected to be an unprecedented moment in multilateralism for the construction of paths that could tackle the multiple facets of malnutrition that afflicts all countries in recent decades. The first indication that the process would not be as expected was the appointment, by António Guterres, Secretary General of the UN, of Agnes Kalibata as Special Envoy with the task of coordinating the event. From the outset, having in this role none other than the president of the Alliance for the Green Revolution in Africa (AGRA) placed agribusiness and corporate interests in privileged positions in the process (CSM 2021).

Although the Summit's recommendations, commitments and results are not binding, the space and visibility given to the topic by a high-level forum are remarkable, which, in addition to defining the directions and strategies of this agenda, directs resources and mobilizes other actors in addition to UN agencies and programmes. In addition to the appointment of a representative of industrial commercial agriculture, the Summit garnered a number of other 
criticisms from academics, civil society organizations and renowned experts for moving away from a legitimate process of convergence ${ }^{1}$.

Scientific evidence, agreed language and concepts, including on multilateral fora, were solemnly ignored. A nutrition example is that many official or working documents of the Summit, for instance from the Action Tracks 1 and $2^{2}$, used 'nutritious' food or diets rather than 'healthy' food or diets. This discussion has already taken place in the negotiations of the Voluntary Guidelines on Food Systems and Nutrition (CFS 2021). Whereas the notion of 'healthy' expands to dimensions beyond biological, 'nutritious' goes in the opposite direction, reducing the scope of healthy food and therefore the range of proposals for its promotion. The nutritional dimension of food is important, however, the nutritional intake and balance is claimed to be achievable, at least theoretically, for example, by supplements and fortification. The concept of 'healthy' includes dimensions such as sustainability and cultural adequacy, that respects and values the different expressions of identities and cultures, which must be guaranteed long before the analysis of the nutrient intake of the meal on the plate.

Building healthy and sustainable food systems means rethinking the whole logic on which the cultivation, processing, supply and consumption of food is based. While large food industries promote ultra-processed food products, agribusiness-based on deforestation, intensive use of pesticides and monoculture of commodities-causes soil deterioration, contamination of watercourses and irreversible impacts on biodiversity and in people's health. This scenario has as a background interested actors favouring this food system model and this is the predominant narrative at the Food Systems Summit.

Moreover, the UN Committee on World Food Security (CFS), the most inclusive multilateral platform for the discussion of issues related to food security and nutrition, was belatedly involved in the Summit elaboration process, in a superfluous and cosmetic way.

It's crucial to fight to bring together different voices and knowledge to build answers and solutions to old problems and new challenges. The voice of civil society needs to be heard. So far, there is a clear preference to focus on the increase in productivity and to favour proposals that deepen inequalities and technological dependence, instead of addressing fundamental issues such as the perspective of human rights and adequate and healthy food, the guarantee

\footnotetext{
${ }^{1}$ Scientists Boycott the 2021 UN Food Systems Summit. https:// agroecologyresearchaction.org/scientists-boycott-the-2021-un-foodsystems-summit/

2 The UN Food Systems Summit organised its five objectives in Action Tracks. https://www.un.org/en/food-systems-summit/actiontracks
}

of food sovereignty, respect and appreciation of traditions, cultures and local knowledge, among others.

Although the event promotes an apparent inclusive structure, from the beginning of the process, the Summit was marked by a non-transparent criterion that left civil society actors and organizations that are legitimate members of food systems in the margins. The so-called multi-stakeholderism approach actually hides a total absence of clear rules of engagement and participation; in fact, such an approach reinforces the giant imbalances of power and interference between large food industries and civil society actors.

With the event influenced by representatives of the food industry and agribusiness, the trend is to deepen the current food systems model that promotes a diet based on ultraprocessed food products- the so-called corporate diets. Not surprisingly, instead of delving into existing healthy food strategies and policies, such as agroecology and regulatory measures, that have already proven effective, the Summit insists on reinforcing false solutions and not looking at structural issues such as the power of companies to promote ultraprocessed foods.

Therefore, in addition to not giving voice to those who actually work and act in food systems and to the practices, solutions and policies that already accumulate robust evidence, such as agroecology (CFS 2019), food-based dietary guidelines (Herforth et al. 2019), NOVA classification (Monteiro et al. 2019), food and nutrition education, school feeding initiatives, and so on, the Summit did not change its course despite the still-growing impacts of the COVID-19 pandemic. It is disconcerting to conclude that the pandemic, which brought and will still bring a series of impacts on food systems, simply 'did not enter the agenda'. As the Special Rapporteur on the Right to Food, Michael Fakhri, stated in an interview to The Guardian: 'The UN summit on food systems took two years to plan. It's offered nothing to help feed families' (The Guardian 2021).

\section{Some Crucial Food Environment Initiatives and Policies to Promote and Protect People and Planet Health}

Ensuring a healthy food environment is an obligation of states that few governments assume and many surrender to market forces. Despite the silence surrounding increased consumption of ultra-processed food products and the strategies to guarantee access to healthy food within the Summit, many countries, particularly in the Latin American region (Popkin 2021), have already excelled in developing regulatory policies to change the food environment to make it easier for the population to make healthy food choices. 


\section{How to Recognize Ultra-processed Food Products and What is Their Impact on Health and the Environment?}

Ultra-processed food products are not exactly food but rather formulations of substances or fractions of food for industrial purposes such as protein isolates or concentrates, esterified oils, hydrogenated fat, modified starches, cosmetic food additives (flavors, emulsifiers, thickeners etc.) and other items for exclusively industrial use. The amounts of fresh foods in ultra-processed food products are usually small or nonexistent. Common examples are soft drinks, dairy drinks, powdered mixture for preparing fruit-flavored drinks, packaged snacks, sweets, and chocolates, 'cereal', ice creams, pre-prepared pizzas, chicken and fish nuggets, and sausages (Nupens 2021).

This concept was first developed by researchers at the University of Sao Paulo in 2009, as part of the NOVA food classification, a pioneering system to organize food by the degree and purpose of processing, that brought more attention to the impact of food processing on human and planetary health (Moubarac et al. 2014; Monteiro et al. 2019). The NOVA food classification has four categories: fresh or minimally processed foods (purchased as fresh products or close to their natural states, such as fresh fruits or packaged rice), culinary ingredients (extracted from raw ingredients and used for cooking, such as oils, salt, and sugar), processed foods (a mixture of the two previous groups, such as a strawberry jam made from the fruit with added sugar), and ultra-processed food products (Nupens 2021).

Since the first studies published by Brazilian researchers, the NOVA classification has influenced research worldwide and demonstrated the harmful influence of ultra-processed products on health and environment. According to several meta-analysis and cohort studies developed in different contexts and populations, the consumption of ultra-processed products triggers weight gain, obesity, diabetes, hypertension, and other cardiovascular diseases, depression, cancers in general, breast cancer, childhood asthma, kidney dysfunctions, and premature deaths. Ultra-processed products have intrinsic characteristics in their composition, processing, consumption and commercialization that explain these negative effects in health, including high energy density, more free sugar, saturated and trans fats, and lower content of dietary fibers, proteins, micronutrients, and bioactive compounds (Nupens 2021).

The impacts of ultra-processed food products also extend to negative consequences for the environment. Increasing evidence has demonstrated the relationship of these food products with biodiversity loss, increasing packaging use, and greenhouse gas emissions.
Ultra-processed food products production requires intensive agricultural systems based on monocultures, high consumption of water and fossil fuels, chemical fertilizers, genetically modified organism (GMO) seeds, pesticides, antibiotics, and long-distance transport.

\section{Reinforcement of Food Based Dietary Guidelines, such as the Dietary Guidelines for the Brazilian Population}

The NOVA classification is the basis of the 2nd edition of the Dietary Guidelines for the Brazilian Population (2014), which has influenced the development of other food guides and other official guidelines for healthy eating in France, Belgium, Canada, and Uruguay and other countries. The international recognition of the Dietary Guidelines for the Brazilian Population represents an important shift in the definition and approach of the recommendations of a healthy and adequate dietary pattern. The paradigm shift from the nutrient-based approach (commonly known as the 'food pyramids') to an overarching food-based approach meant the inclusion of the perspective of the promotion of environmental and socio-economic sustainability, healthy eating patterns, and the protection of food cultures. The recommendation of 'always prefer fresh or minimally processed food and cooking preparations to ultra-processed foods' is straightforward and easily understandable. Finally, the systemic approach of the recommendations contributes to triggering cohesive policymaking in different governmental sectors, involving the entire supply chain.

It is remarkable how the most recent surveys confirm and consolidate the NOVA Classification perspective, reaffirming the importance of this paradigm shift in the construction of recommendations for healthy and sustainable diets.

\section{Reinforcement of Regulatory Measures such as Front of Package Nutrition Labeling, Soft Drink taxations, Marketing Restrictions and Others}

Regulatory measures to discourage the consumption of ultraprocessed food products have been widely recognized as the most effective approach to prevent and reduce diet related NCDs, and therefore contribute to healthier food systems transformations (Popkin et al. 2021). These measures are based on the need to regulate food environments, as opposed to simply individual products, so that individuals can have facilitated access to healthier and affordable foods.

The adoption of warning front-of-package nutrition labels (FOPNL) with the Nutrition Profile Model of the Pan American Health Organization (PAHO) represents the most effective approach to discouraging the purchase of ultra-processed products (PAHO 2020). It stands out as an informative symbol inserted on the main panel of food 
labels to inform the consumer simply and clearly about the high content of nutrients associated with health issues, such as salt, sugar, and fat. The warning format supported by PAHO and adopted in Chile, Mexico, Peru and Uruguay, prompts the best performance and understanding of consumers (PAHO 2020). To increase the impact of warning FOPNL models, other approaches can be adopted to regulate nutrition and health claims, prohibit misleading advertising practices on labels and adopt highlighted information on the presence of cosmetic additives on food labels.

Another effective measure adopted by several countries is a fiscal policy for taxing sweetened beverages, especially soft drinks and promoting price reduction and to promote fresh or minimally processed foods and culinary preparations. The measure is supported by scientific evidence showing that the tax discourages the consumption of these products, encouraging the consumption of healthier and cheaper options, such as water (WHO 2017; Allcott et al. 2019).

Regarding the promotion and protection of a healthy school environment, schools should be priority spaces of adequate and healthy food, with regulatory approaches to restrict ultra-processed food products in the school's canteens and foods purchased from public procurement such as the Brazilian School Feeding Program (PNAE, in Portuguese). However, research has shown that, currently, the school environment systematically contributes to the adoption of eating practices considered not healthy, playing an important role in overweight and obesity rates (Boklis et al. 2021).

In addition to schools, restriction of marketing of ultraprocessed food products, especially for children also needs to be prioritized, as this population is developing and acquiring maturity to face adulthood, and is more vulnerable to abusive marketing practices. Advertising interferes negatively in this age group, encouraging the excess consumption of unhealthy foods and options. Advertising aimed at this audience should be banned and considered abusive and illegal (Guimarães et al. 2021.

These regulatory measures for food environments are recommended by the World Health Organization (WHO) and PAHO and should be aligned with healthy eating recommendations based on the degree and purpose of industrial food processing. Latin American countries have stood out as the region with more implemented and effective regulations to reduce the consumption of ultra-processed food products. Mexico, Chile, Peru, and Uruguay, for example, implemented combined and synergic policies to increase taxation, foment warning FOPNL on unhealthy products, and limit marketing strategies targeting children (Taillie et al. 2020; Basto-Abreu et al. 2020; Ares et al. 2021).

\section{Looking Ahead: Reinforcing Protection and Promotion Policies that Transform Food Systems on a Right to Food Perspective/ Principle}

Expanding the scope of food systems, previously restricted to the so-called value chain for the entire set of dimensions, processes, subjects and institutions 'from the earth to the plate' demands, on the basis of assuring health and sustainability of the planet and societies, that determinants of consumption beyond individual choice issues are analyzed. This comprehensive analysis makes it possible to define strategies that have potential to change the health and nutrition conditions of entire populations.

Evidence indicates that the necessary level of change in dietary patterns depends on measures that alter structural aspects of food systems and environments (IPES-Food and ETC Group 2021). Thus, a large part of these measures needs to be harmonized beyond national spaces, considering the global circulation of products and information. This is one of the great challenges of this agenda, given the emptying of governance spaces, the weakening of the regulatory capacity of states and the growing interference of corporations.

The adoption of neoliberal policies in many countries has demonstrated that, under the excuse of reducing the size of the state, too much space has been opened up for markets, and what appeared to be an immediate economy has enormous costs in terms of human dignity and life. Circumstances like these make it clear the need for a strong state with solid healthy food policies based on human rights and not relying exclusively on emergency and solidarity actions.

In this sense, governance spaces, such as the CFS, and other experiences at subnational levels, such as the Food and Nutrition Security Councils (CONSEA) in Brazil, when protected from conflict of interest, are key salutary spaces for dialogue and collective construction of policies and strategies to face common challenges and problems. It is necessary to reflect on and expose who benefits from the weakening and emptying of these spaces of participation. An additional direct consequence of the emptying of spaces for participation is the weakening of the regulatory role of states and policy inertia, thus privileging private corporate interests over the collective interests of health and public welfare.

Another fundamental aspect that deserves to be highlighted is the urgent need for a change in the paradigm that governs food and nutrition education strategies (Brazil 2012). If healthy and sustainable diets is far beyond the perfect combination of nutrients, education necessarily needs to encompass these multiple dimensions to promote 
the critical capacity, autonomy, and skills of people and communities. This education must support the appreciation of different cultures and food heritages.

The response to the COVID pandemic and the different layers of inequities that many regions face, could be the opportunity for significant and structural changes in food systems. The criticism directed at the organization of the Food Systems Summit demonstrates that there are many voices opposing the agenda this event endorses, and that they are united around common causes such as the rejection of corporate food systems.

The nexus between health-food and sustainability needs to be widely publicized so that the costs and consequences of the corporate food production and consumption model are fully recognized by citizens (IPES-Food 2017). This awareness can generate a critical mass that paves the way to necessary changes. This awareness must be expressed in broad, representative and democratic processes so that the holders of rights have an active and informed participation in the discussion and decision processes.

Funding All authors have seen and agree with the contents of the manuscript and there is no financial interest to report.

\section{Declarations}

Conflict of interest The authors have no conflicts of interest to declare.

Consent for publication We certify that the submission is original work and is not under review at any other publication.

\section{References}

Allcott, Hunt, Benjamin B. Lockwood, and Dmitry Taubinsky. 2019. Should We Tax Sugar-Sweetened Beverages? An Overview of Theory and Evidence. Journal of Economic Perspectives 33 (3): 202-227. https://doi.org/10.1257/jep.33.3.202.

Alsaffar, Ayten Aylin. 2016. Sustainable diets: The interaction between the food industry, nutrition, health and the environment. Food Science and Technology International 22 (2): 102-111. https:// doi.org/10.1177/1082013215572029.

Ares, Gastón, Lucía Antúnez, María Rosa. Curutchet, Luis Galicia, Ximena Moratorio, Ana Giménez, and Isabel Bove. 2021. Immediate effects of the implementation of nutritional warnings in Uruguay: Awareness, self-reported use and increased understanding. Public Health Nutrition 24 (2): 364-375. https://doi.org/10.1017/ S1368980020002517.

Basto-Abreu, Ana, Rossana Torres-Alvarez, Francisco Reyes-Sánchez, Romina González-Morales, M. Francisco Canto-Osorio, Arantxa Colchero, Simón Barquera, Juan A. Rivera, and Tonatiuh Barrientos-Gutierrez. 2020. Predicting obesity reduction after implementing warning labels in Mexico: A modeling study. PLoS Medicine 17 (7): e1003221. https://doi.org/10.1371/journal.pmed.1003221.

Berkhout, Esmé. Nick Galasso, Max Lawson, Pablo Andrés Rivero Morales, Anjela Taneja and Diego Alejo Vázquez Pimentel. 2021. The Inequality Virus: Bringing Together A World Torn Apart By
Coronavirus Through A Fair, Just And Sustainable Economy. Oxford: Oxfam International. Retrieved from: https://www.oxfam. org/en/research/inequality-virus.

Boklis-Berer, Mirena, Fernanda Rauber, Catarina Machado Azeredo, Renata Bertazzi Levy, Maria Laura, and da Costa Louzada. 2021. The adherence to school meals is associated with a lower occurrence of obesity among Brazilian adolescents. Preventative Medicine 150: 106709. https://doi.org/10.1016/j.ypmed.2021.106709.

Brasil. Ministério do Desenvolvimento Social e Combate à Fome. 2012. Marco de Referência de Educação Alimentar e Nutricional para as Políticas Públicas. https://www.cfn.org.br/wp-content/ uploads/2017/03/marco_EAN.pdf. Accessed 15 September 2021

Canfield, Matthew C., Molly D. Anderson, and Philip McMichael. 2021. UN Food Systems Summit 2021: Dismantling Democracy and Resetting Corporate Control of Food Systems. Frontiers in Sustainable Food Systems 5: 103. https://doi.org/10.3389/fsufs. 2021.661552.

CFS. 2019. The High Level Panel of Experts on Food Security and Nutrition. Agroecological and other innovative approaches. Report 14. http://www.fao.org/3/ca5602en/ca5602en.pdf Accessed 10 September 2021.

Civil Society and Indigenous Peoples' Mechanism. 2020. Voices from the ground: From COVID-19 to radical transformation of our food systems. https://www.csm4cfs.org/wp-content/uploads/2020/12/ EN-COVID_FULL_REPORT-2020.pdf, accessed 21 September 2021.

Civil Society and Indigenous Peoples' Mechanism. 2021. CSM response to the invitation to join the UN Food Systems pre-Summit Synthesis Plenary. https://www.csm4cfs.org/csm-response-to-theinvitation-by-ms-kalibata-to-join-the-un-food-systems-pre-summit/ Accessed 21 September 2021.

Committee on Food Security (CFS). 2021. Voluntary Guidelines on Food Systems and Nutrition, https://www.google.com/url?q= http://www.fao.org/fileadmin/templates/cfs/Docs2021/Docum ents/CFS_VGs_Food_Systems_and_Nutrition_Strategy_EN.pdf\& $\mathrm{sa}=\mathrm{D} \&$ source $=$ editors \&ust $=1632333734147000 \& u s g=\mathrm{AOvVa}$ w3jIVGk7EfPJOEFUhwgbVEg. Accessed 18 September 2021.

De Laurentiis, Valeria, Dexter V.L. Hunt, and Christopher D.F. Rogers. 2016. Overcoming Food Security Challenges within an Energy/ Water/Food Nexus (EWFN) .Approach Sustainability 8(1), 95. https://doi.org/10.3390/su8010095

FAO, IFAD, UNICEF, WFP and WHO. 2021. The State of Food Security and Nutrition in the World 2021. Transforming food systems for food security, improved nutrition and affordable healthy diets for all. Rome, FAO. https://doi.org/10.4060/cb4474en.

Franck, Anouk, and Art Prapha. 2021. Not in This Together: How supermarkets became pandemic winners while women workers are losing out. Oxford: Oxfam.

GBD. 2015. Risk Factors Collaborators. 2016. Global, regional, and national comparative risk assessment of 79 behavioural, environmental and occupational, and metabolic risks or clusters of risks, 1990-2015: a systematic analysis for the Global Burden of Disease Study. Lancet 388(10053): 1659-1724. https://doi.org/10. 1016/S0140-6736(16)31679-8.

Global Health Advocacy Incubator. 2020. Facing Two Pandemics How Big Food Undermined Public Health in the Era of COVID19, https://advocacyincubator.org/wp-content/uploads/2020/ 11/GHAI-Facing-Two-Pandemics-Report-November-2020.pdf Accessed 20 September 2021.

Gneiting, Uwe, Nicholas Lusiani, and Irit Tamir. 2020. Power, Profits and the Pandemic. From corporate extraction for the few to an economy that works for all. Oxford: Oxfam. https://www.oxfam. org/en/research/power-profits-and-pandemic

Guimarães, Julia S., Laís. A. Mais, Fernanda H.M.. Leite, Paula M. Horta, Marina O. Santana, Ana P.B.. Martins, and Rafael M. Claro. 2021. Abusive advertising of food and drink products on 
Brazilian television. Health Promotion International. https://doi. org/10.1093/heapro/daab025.

Herforth, Anna, Mary Arimond, Cristina Álvarez-Sánchez, Jennifer Coates, Karin Christianson, and Ellen Muehlhoff. 2019. A Global Review of Food-Based Dietary Guidelines. Advances in Nutrition 10 (4): 590-605. https://doi.org/10.1093/advances/nmy 130.

ILO monitor 7th edition. 2021. ILO: Uncertain and uneven recovery expected following unprecedented labour market crisis. 25 January. https://www.ilo.org/global/ about-the-ilo/newsroom/news/ WCMS_766949/lang--en/index.htm

IPES-Food and ETC Group. 2021. A Long Food Movement: Transforming Food Systems by 2045. http://www.ipes-food.org/img/upload/ files/LongFoodMovementEN.pdf Accessed 10 September 2021.

IPES-Food. 2017. Unravelling the Food-Health Nexus: Addressing practices, political economy, and power relations to build healthier food systems. The Global Alliance for the Future of Food and IPES-Food. http://www.ipes-food.org/_img/upload/files/Health_ FullReport(1).pdf Accessed 10 September 2021.

Mendes, Larissa Loures, Daniela Silva Canella, Melissa Luciana, Mariana de Araújo, Zogbi Jardim, Letícia de Oliveira Cardoso, and Milene Cristine Pessoa. 2021. Food environments and the COVID-19 pandemic in Brazil: Analysis of changes observed in 2020. Public Health Nutrition. https://doi.org/10.1017/S1368 980021003542.

Monteiro, Carlos A., Geoffrey Cannon, Renata B. Levy, Jean-Claude. Moubarac, Maria L.C.. Louzada, Fernanda Rauber, Neha Khandpur, Gustavo Cediel, Daniela Neri, and Euridice Martinez-Steele. 2019. Ultra-processed foods: What they are and how to identify them. Public Health Nutrition 22 (5): 936-941. https://doi.org/10. 1017/S1368980018003762.

Moubarac, Jean-Claude., Diana C. Parra, Geoffrey Cannon, and Carlos A. Monteiro. 2014. Food classification systems based on food processing: significance and implications for policies and actions: a systematic literature review and assessment. Current Obesity Repports 3: 256-272. https://doi.org/10.1007/s13679-014-0092-0.

Nupens, Cátedra Josué de Castro, USP. 2021. Dialogue on Ultraprocessed food products: Solutions for Healthy and Sustainable Food Systems. https://www.fsp.usp.br/nupens/wp-content/uploa ds/2021/06/Documento-Dia\%CC\%81logo-Ultraprocessados_EN. pdf accessed 15 September 2021.

Pan American Health Organization. 2020. Front-of-Package Labeling as a Policy Tool for the Prevention of Noncommunicable Diseases in the Americas PAHO/NMH/RF/20-0033, https://iris.paho.org/ bitstream/handle/10665.2/52740/PAHONMHRF200033_eng.pdf? sequence $=6$ Accessed 15 September 2020 .

Popkin, Barry M., Simon Barquera, Camila Corvalan, Karen J. Hofman, Carlos Monteiro, Shu Wen Ng, Elizabeth C. Swart, and Lindsey Smith Taillie. 2021. Towards unified and impactful policies to reduce ultra-processed food consumption and promote healthier eating. Lancet Diabetes and Endocrinology 9 (7): 462 470. https://doi.org/10.1016/S2213-8587(21)00078-4.

Intergovernmental Panel on Climate Change. 2021. Summary for Policymakers. In Climate Change 2021: The Physical Science
Basis. Contribution of Working Group I to the Sixth Assessment Report of the Intergovernmental Panel on Climate Change, eds. Masson-Delmotte, V., P. Zhai, A. Pirani, S. L. Connors, C. Péan, S. Berger, N. Caud, Y. Chen, L. Goldfarb, M. I. Gomis, M. Huang, K. Leitzell, E. Lonnoy, J. B. R. Matthews, T. K. Maycock, T. Waterfield, O. Yelekçi, R. Yu and B. Zhou. Cambridge University Press (In press).

Swinburn, Boyd A., Vivica I. Kraak, Steven Allender, Vincent J. Atkins, Phillip I. Baker, Jessica R. Bogard, Hannah Brinsden, Alejandro Calvillo, Olivier De Schutter, Raji Devarajan, Majid Ezzati, Sharon Friel, Shifalika Goenka, Ross A. Hammond, Gerard Hastings, Corinna Hawkes, Mario Herrero, Peter S. Hovmand, Mark Howden, Lindsay M. Jaacks, Ariadne B. Kapetanaki, Matt Kasman, Harriet V. Kuhnlein, Shiriki K. Kumanyika, Bagher Larijani, Tim Lobstein, Michael W. Long, Victor K.R.. Matsudo, Susanna D.H.. Mills, Gareth Morgan, Alexandra Morshed, Patricia M. Nece, An. Pan, David W. Patterson, Gary Sacks, Meera Shekar, Geoff L. Simmons, Warren Smit, Ali Tootee, Stefanie Vandevijvere, Wilma E. Waterlander, Luke Wolfenden, and William H. Dietz. 2019. The global syndemic of obesity, undernutrition, and climate change: the lancet commission report. Lancet 393 (10173): 791-846. https://doi.org/10.1016/S0140-6736(18) 32822-8.

Taillie, Lindsey Smith, M. Marcela Reyes, Arantxa Colchero, Barry Popkin, and Camila Corvalán. 2020. An evaluation of chile's law of food labeling and advertising on sugar-sweetened beverage purchases from 2015 to 2017: a before-and-after study. PLoS Medicine 17 (2): e1003015. https://doi.org/10.1371/journal.pmed. 1003015.

The Guardian. 2021. The UN summit on food systems took two years to plan. It's offered nothing to help feed families. 23 September, Michael Fakhri, https://www.theguardian.com/global/comme ntisfree/2021/sep/23/un-summit-food-systems-families-micha el-fakhri.

The Lancet Diabetes and Endocrinology. 2021. Food policies: in times of COVID-19 and beyond. The Lancet Diabetes and Endocrinology 9(6): 319, https://doi.org/10.1016/s2213-8587(21)00123-6

WHO. 2017. Taxes on sugary drinks: Why do it?, WHO. https://apps. who.int/iris/bitstream/handle/10665/260253/WHO-NMH-PND16.5Rev.1-eng.pdf;sequence $=1$

World Bank. 2020. COVID-19 to plunge global economy into worst recession since World War II. 8 June. https://www.worldbank. org/en/news/press-release/2020/06/08/covid-19-to-plunge-globa leconomy-into-worst-recession-since-world-war-ii Accessed 1 June 2021.

Publisher's Note Springer Nature remains neutral with regard to jurisdictional claims in published maps and institutional affiliations. 